\title{
Hydrophobic Cryogels Based on Polyvinyl Alcohol and Polymeric Oil Resins
}

\author{
Maria S. Fufaeva*a, \\ Darya V. Fisenko ${ }^{b}$, Vladimir N. Manzhaya, \\ Vladimir G. Bondaletov ${ }^{\mathrm{b}}$ and Lyubov K. Altunina ${ }^{\mathrm{a}}$ \\ ${ }^{a}$ Institute of Petroleum Chemistry SB RAS \\ 4 Akademichesky, Tomsk, 634055, Russia \\ ${ }^{b}$ National Research Tomsk Polytechnic University \\ 30 Lenin, Tomsk, 634050, Russia
}

Received 26.10.2018, received in revised form 24.12.2018, accepted 09.04.2019

The paper presents the results of studies of the flow properties of viscous compositions consisting of polyvinyl alcohol, polymeric oil resin, and water. After a freeze-thaw cycle three-component cryogels are formed from them. Mechanical, thermal, physical, and chemical properties of the resulted elastic samples are studied. The prospects of using hydrophobic cryogels filled with polymeric oil resin as a binder component for road pavement construction are presented.

Keywords: polyvinyl alcohol, solution, polymer oil resin, viscosity, cryogel, hydrophobicity, modulus of elasticity.

Citation: Fufaeva M.S., Fisenko D.V., Manzhay V.N., Bondaletov V.G., Altunina L.K. Hydrophobic cryogels based on polyvinyl alcohol and polymeric oil resins, J. Sib. Fed. Univ. Chem., 2019, 12(2), 166-176. DOI: 10.17516/1998-2836-0116.

(c) Siberian Federal University. All rights reserved

* Corresponding author E-mail address: maria81@ipc.tsc.ru 


\title{
Криогели на основе поливинилового спирта \\ и нефтеполимерных смол с гидрофобными свойствами
}

\author{
М.С. Фуфаева ${ }^{a}$, Д.В. Фисенко ${ }^{0}$, \\ В.Н. Манжайа ${ }^{\mathrm{a}}$ В.Г. Бондалетов ${ }^{\tilde{0}}$, Л.К. Алтунина ${ }^{\mathrm{a}}$ \\ ${ }^{a}$ Институт химии нефти СО РАН \\ Россия, 634055, Томск, пр. Академический, 4 \\ ${ }^{6}$ Национальный исследовательский \\ Томский политехнический университет \\ Россия, 634050, Томск, пр. Ленина, 30
}

В работе представлены результаты исследований реологических свойств вязкотекучих композиций, состоящих из поливинилового спирта, нефтеполимерной смоль и воды. После цикла замораживания - оттаивания из них сформированы трехкомпонентные криогели и изучены механические, теплофизические и физико-химические свойства полученных упругих образиов. Указана перспективность использования гидрофобных криогелей, наполненных нефтеполимерной смолой, в качестве связующего компонента при бытовом и дорожном строительстве асфальтовых покрытий.

Ключевые слова: поливиниловый спирт, раствор, нефтеполимерная смола, вязкость, криогель, гидрофобность, модуль упругости.

\section{Введение}

Создание новых композиционных материалов, предназначенных для разработки перспективных технологий, признано актуальным направлением прикладной химии. Замораживание вязкотекучих водных растворов поливинилового спирта (ПВС), их выдерживание в кристаллическом состоянии (при температуре $\mathrm{T}<0{ }^{\circ} \mathrm{C}$ ) на протяжении нескольких часов и последующее оттаивание в области положительных температур (при $\mathrm{T}>0{ }^{\circ} \mathrm{C}$ ) приводит к образованию упругих криогелей (каучукоподобных тел), т.е. наблюдается переход двухкомпонентных растворов из жидкого агрегатного состояния в твердое без использования «сшивающих» химических реагентов $[1,2]$. Криогели, сформированные в условиях кристаллизации растворителя, термообратимы, но плавятся они при температуре на несколько десятков градусов выше температуры структурирования растворов. Криогели являются нетоксичным и экологически чистым материалом, обладают рядом других полезных свойств, которые позволяют применять их в медицине, биотехнологии, пищевой промышленности [1]. После введения в матрицу криогелей гидрофобных материалов они могут быть также использованы при добыче и транспорте нефти [3], при формировании гидроизолирующих экранов для предотвращения нежелательной фильтрации воды через стенки и днища гидротехнических сооружений $[4,5]$, а также в промышленном и дорожном строительстве. В качестве гидрофобных наполнителей чаще всего используют минеральные и растительные масла, сажу и т.д. [6-8].

$$
-167-
$$


Введение в полимерную композицию криогеля модификаторов и наполнителей в значительной степени изменяет структурно-механические, теплофизические и физико-химические свойства материала. В данной работе в качестве гидрофобного наполнителя применяли нефтеполимерную смолу (НПС), представляющую собой олигомерный продукт из мономеров непредельных углеводородов, которые являются продуктами пиролиза бензина $[5,9]$. Замена в матрице криогеля эмульгированного минерального масла на нефтеполимерную смолу обусловлено тем, что для изделий из полимеров характерно «выпотевание» пластификатора, т.е. самопроизвольный выход из внутреннего объема тела на его поверхность. Использование вместо минерального масла (смеси относительно низкомолекулярных углеводородов) нефтеполимерных смол, имеющих более высокие молекулярные массы в диапазоне $\mathrm{M} \sim 500$ - 3000 [10], значительно замедляет диффузию крупных молекул на поверхность полимерной матрицы, состоящей из структурированных молекул ПВС, и тем самым значительно улучшает эксплуатационные свойства гидроизолирующих экранов.

Цель работы - разработка состава и исследование свойств гидроизоляционной композиции, обладающей высокой адгезией и гидрофобностью, способной сохранять свои физикомеханические характеристики в течение долгого времени при значительных перепадах температур во влажной среде.

\section{Экспериментальная часть}

Для приготовления исходного водного раствора полимера (дисперсионная среда) использовали образец поливинилового спирта с молекулярной массой $\mathrm{M} \approx 150 \cdot 10^{3}$, содержащий в своей структуре не более $1 \%$ остаточных ацетатных групп после проведенного гидролиза поливинилацетата.

В качестве гидрофобного наполнителя взяли нефтеполимерную смолу, которую получают каталитической полимеризацией фракции жидких продуктов промышленного пиролиза прямогонного бензина $[9,11]$. Фракция в своем составе содержит непредельные углеводороды ароматического ряда (стирол, $\alpha$-метилстирол, дициклопентадиен, инден и др.), количество которых достигает 70 \%. Данная смола производится в промышленном масштабе под названием Пиропласт. Растворителем для приготовления растворов НПС служил нефтяной сольвент или дизельное топливо.

Для стабилизации прямой эмульсии, получаемой из водного раствора ПВС и раствора НПС, использовали поверхностно-активное вещество Неонол АФ 9-12. Этот оксиэтилированный алкилфенол на основе тримера пропилена представляет собой техническую смесь полиэтиленгликолевых эфиров моноалкилфенолов следующего состава $\mathrm{C}_{9} \mathrm{H}_{19} \mathrm{C}_{6} \mathrm{H}_{4} \mathrm{O}\left(\mathrm{C}_{2} \mathrm{H}_{4} \mathrm{O}\right)_{n} \mathrm{H}$, где $\mathrm{C}_{9} \mathrm{H}_{19}-$ алкильный радикал, присоединенный к фенолу преимущественно в пара-положении к гидроксильной группе; $\mathrm{n}=12$ - усредненное число молей окиси этилена, присоединенное к одному молю алкилфенолов [12].

Приготовление эмульсий проводили с помощью роторного диспергатора IKA ULTRA TURRAXT18. Время диспергирования 5-10 мин. Скорость вращения ротора 15000 18000 об/мин. Устойчивость эмульсий оценивали временем (t, мин) нахождения во взвешенном состоянии микроскопических капелек НПС, нерастворимых в водном растворе ПВС. Дестабилизацию эмульсии определяли по появлению в мерном цилиндре нижнего слоя воды или 
верхнего слоя в виде раствора смолы, которые со временем хранения увеличивались в объеме или оставались без изменения в зависимости от концентрации НПС и ПВС в коллоидной системе.

Измерение динамической вязкости ( и НПС) и их эмульсий проводили на ротационном вискозиметре «Реотест-2» при разных температурах $\left(\mathrm{T},{ }^{\circ} \mathrm{C}\right)$ в широком диапазоне скоростей сдвига $\left(\mathrm{j}, \mathrm{c}^{-1}\right)$.

Для получения двухкомпонентных криогелей (ПВС - вода) полимерные растворы различной концентрации заливали в цилиндрические ячейки и замораживали при температуре минус $20^{\circ} \mathrm{C}$ [8]. Затем твердые образцы размораживали при комнатной температуре $20^{\circ} \mathrm{C}$. После цикла замораживания - оттаивания получали упругие криогели. Аналогичным способом в ячейках получали и криогели из эмульсий.

Сформированным эластичным образцам криогелей задавали относительную деформацию $(\gamma)$ и измеряли упругое напряжение (Р, Па), возникающее в материале. Далее по формуле Гука рассчитывали модуль упругости $(\mathrm{G}$, Па).

Температуру плавления криогелей $\left(\mathrm{T}_{\text {пл., }}{ }^{\circ} \mathrm{C}\right)$ определяли методом «падающего шарика», который описан в работе [13]. Для этого образец криогеля помещали в цилиндрический сосуд, на дне которого находился шарик из нержавеющей стали. Стеклянный сосуд с криогелем запаивали, ставили в сушильный шкаф при начальной температуре $50^{\circ} \mathrm{C}$ и увеличивали температуру с шагом в $1{ }^{\circ} \mathrm{C}$. Образцы выдерживали при каждой температуре не менее 15 мин. За точку плавления принимали температуру, при которой шарик, проходя через слой плавящегося геля, падал на дно сосуда.

Теплоизоляционные свойства криогелей оценивали по величине коэффициента теплопроводности ( $\lambda$, Вт/К·м), которую определяли на установке; основным рабочим узлом установки являются два стальных коаксиальных цилиндра, в зазоре между которыми помещена исследуемая среда $[14,15]$. Значение коэффициента теплопроводности рассчитывали по формуле:

$$
\lambda=\mathrm{Q} \cdot \ln \left(\mathrm{R}_{1} / \mathrm{R}_{2}\right) / 2 \pi \cdot \mathrm{L} \cdot \mathrm{t} \cdot\left(\mathrm{T}_{0}-\mathrm{T}\right),
$$

где $\mathrm{R}_{1}$ - внутренний радиус большого цилиндра; $\mathrm{R}_{2}$ - наружный радиус малого цилиндра; $\mathrm{Q}$ количество тепла, передаваемое от нагретой воды термостата к воде внутреннего цилиндра; $\mathrm{L}$ - высота малого цилиндра; T - текущая температура воды во внутреннем цилиндре в некоторый момент времени (t); $\mathrm{T}_{0}$ - температура теплоносителя в термостате.

О гидроизоляционных свойствах криогелей, наполненных гидрофобной НПС, судили по интенсивности абсорбции воды, которую определяли гравиметрическим методом, и количественно характеризовали степенью набухания при контакте образцов с водой в течение 20 сут. Степень набухания $(\alpha, \%)$ криогеля рассчитывают по формуле

$$
\alpha=\frac{\mathrm{m}-\mathrm{m}_{0}}{\mathrm{~m}_{0}} \cdot 100 \%,
$$

где $\mathrm{m}_{\mathrm{o}}$ - масса исходного образца криогеля; $\mathrm{m}$ - масса набухшего криогеля.

Степень гидрофобности поверхности композитного криогеля определяли методом компьютерного видеосканирования. На поверхность полученных криогелей наносили капли воды, регистрировали через микроскоп изменение размера капель. С помощью программы компью- 
терной обработки изображения вычислили площадь, которую занимает капля воды через определенное время. Степень гидрофобности $(\beta, \%)$ криогеля рассчитывали по формуле

$$
\beta=\frac{S_{0}-S_{1}}{S_{0}} \cdot 100 \%
$$

где $\mathrm{S}_{0}$ - площадь капли воды в начальный момент времени; $\mathrm{S}_{1}$ - площадь капельки воды через $300 \mathrm{c}$.

При формировании исходных многокомпонентных эмульсий следует учитывать, что увеличение концентрации ПВС в дисперсионной среде или содержание гидрофобного наполнителя в дисперсной фазе способствует росту вязкости коллоидной системы [7]. Вязкие свойства являются следствием межмолекулярного взаимодействия, которые не только препятствуют течению жидкостей, но и затрудняют их механическое диспергирование. Поэтому для получения высокодисперсных и устойчивых эмульсий необходимо контролировать их реологические свойства, также оказывающие существенное влияние на конечные продукты (криогели).

Из данных рис. 1 следует, что введение дисперсии НПС в водный раствор ПВС сопровождается не только резким увеличением вязкости системы, но и заметным проявлением у эмульсий неньютоновских свойств. Необходимо также отметить наибольшую вязкость эмульсии, содержащей НПС, которая растворена в сольвенте, по сравнению с раствором смолы в дизельном топливе (рис. 1, кривые 1 и 2). Это объясняется тем, что сольвент вследствие высокой доли ароматических соединений близкий по химической природе растворитель для НПС и в нем олигомерные молекулы смолы имеют наиболее развернутые конформации. Следствием этого является экспериментально наблюдаемое наличие наибольшей упругости у криогелей (рис. 2), сформированных из эмульсий, содержащих микрокапли НПС в сольвенте. Кривые рис. 1 также подтверждают характерную особенность криогелей $[1,2]$, в соответствии с кото-

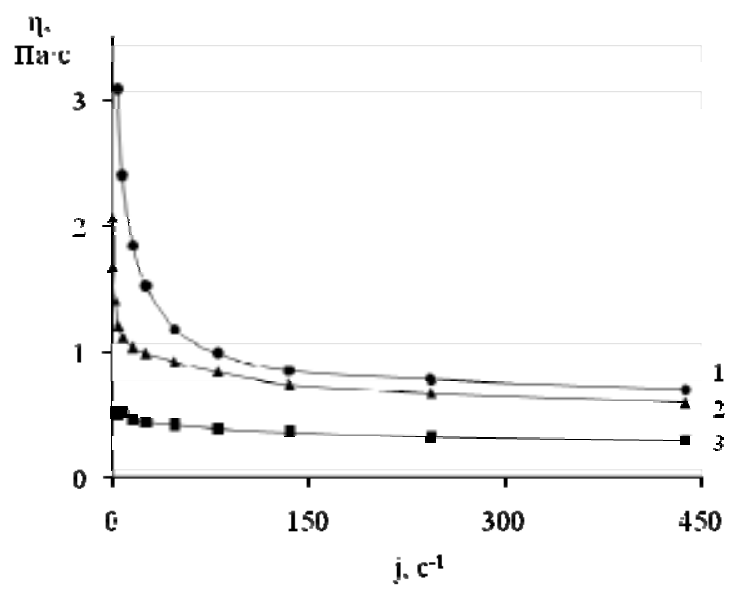

Состав вязкотекучих систем:

1 - ПВС $100 \Gamma^{\cdot} \pi^{-1} ;$ НПС $300 \Gamma \cdot \pi^{-1}$ (в сольвенте);

2 - ПВС $100 \Gamma^{\cdot} \pi^{-1} ;$ НПС $300 \Gamma^{\cdot} \pi^{-1}$ (в дизельном топливе);

$3-$ ПВС $100 \Gamma \cdot \pi^{-1}$

Рис. 1. Зависимость динамической вязкости $\eta$ системы от скорости сдвига ј при температуре $20^{\circ} \mathrm{C}$

Fig. 1. Dependence of the dynamic viscosity $\eta(\mathrm{Pa} \cdot \mathrm{s})$ of the system on the shear rate $\mathrm{j}\left(\mathrm{s}^{-1}\right)$ at a temperature of $20{ }^{\circ} \mathrm{C}$ 


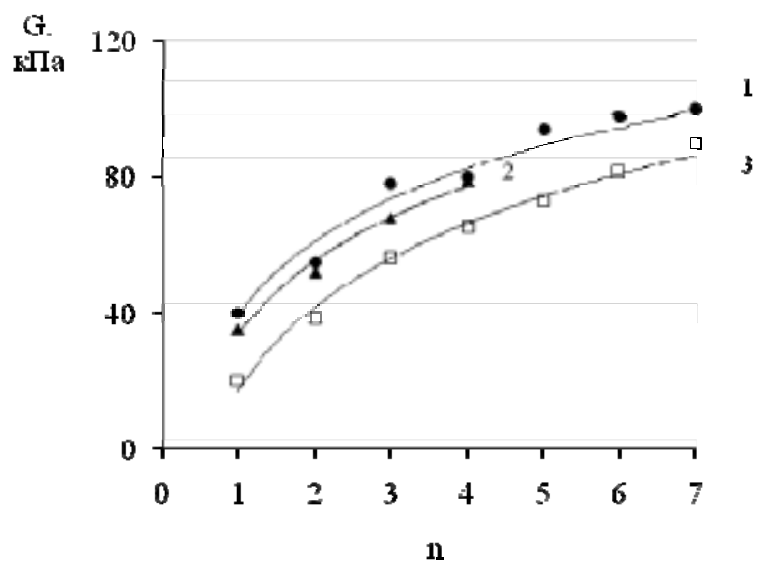

Состав композиций:

1 - ПВС $100 \Gamma^{\cdot} \cdot \pi^{-1} ;$ НПС $300 \Gamma \cdot \pi^{-1}$ (в сольвенте);

2 - ПВС $100 \Gamma^{\cdot} \cdot \pi^{-1} ;$ НПС $300 \Gamma^{\cdot} \pi^{-1}$ (в дизельном топливе);

$3-\Pi$ ПВС $100 \Gamma \cdot \pi^{-1}$

Рис. 2. Зависимость модуля упругости $\mathrm{G}$ (кПа) криогеля от числа циклов (n) замораживания размораживания

Fig. 2. Dependence of the modulus of elasticity $\mathrm{G}(\mathrm{kPa})$ of a cryogel on the number of freezing-thawing cycles (n)

рой увеличение числа циклов замораживания - оттаивания (n) сопровождается ростом модуля упругости $(\mathrm{G})$.

С практической точки зрения для получения криогелей целесообразно в исходной композиции использовать полимерный компонент в наименьших количествах, т.е. формировать криогели из растворов с минимальной концентрацией ПВС $\sim 50 \Gamma^{\circ} \cdot{ }^{-1}$, ниже которой у водных растворов образца полимера с приведенными молекулярными характеристиками криоструктурирование не наблюдается [8]. Результаты исследования структурномеханических, теплофизических и физико-химических свойств некоторых образцов криогелей, сформированных после одного цикла замораживания - оттаивания по описанной выше методике, представлены в табл. 1. Там приведены следующие значения: время устойчивости эмульсии $(\mathrm{t})$, модуль упругости образцов криогелей $(\mathrm{G})$, температура плавления (т. пл.) и коэффициент теплопроводности $(\lambda)$, степень набухания образцов $(\alpha)$ и степень их гидрофобности ( $\beta)$.

Анализ экспериментальных результатов, приведенных в табл. 1, показывает, что введение НПС в полимерную матрицу криогелей сопровождается заметным увеличением упругости структурированных систем и незначительным снижением температуры их плавления, а также полуторакратным улучшением теплоизоляционных свойств по сравнению с двухкомпонентным криогелем (табл. 1, строка 1), полученным из водного раствора ПВС (50 г·л $\left.{ }^{-1}\right)$. При этом образцы любых составов в воде не растворяются и практически не набухают. Замечательной особенностью криогелей, наполненных НПС, является их гидрофобность. После нанесения капли воды на поверхность криогелей, полученных из эмульсии, наблюдается уменьшение площади смачивания с увеличением краевого угла. 
Таблица 1. Устойчивость эмульсий и свойства сформированных из них криогелей

Table 1. Stability of emulsions and properties of cryogels formed from them

\begin{tabular}{|c|c|c|c|c|c|c|c|}
\hline № & Состав системы, фаза/среда & $\begin{array}{c}\mathrm{t}, \\
\text { мин }\end{array}$ & $\begin{array}{c}\mathrm{G}, \\
\text { кПа }\end{array}$ & $\begin{array}{l}\mathrm{T}_{\text {пл, }}, \\
{ }^{\circ} \mathrm{C}\end{array}$ & $\begin{array}{c}\lambda, \\
\mathrm{BT} / \mathrm{K} \cdot \mathrm{M}\end{array}$ & $\begin{array}{l}\alpha, \\
\%\end{array}$ & $\begin{array}{l}\beta, \\
\%\end{array}$ \\
\hline 1 & ПВС $\left(50 \Gamma \cdot \pi^{-1}\right)$ & - & 11 & 70 & 0,34 & 4 & - \\
\hline 2 & НПС $\left(100 \Gamma \cdot \pi^{-1}\right) / \Pi В С\left(50 \Gamma \cdot \pi^{-1}\right)$ & 300 & 45 & 69 & 0,24 & 3 & 42 \\
\hline 3 & НПС $\left(200 \Gamma \cdot \pi^{-1}\right) / \Pi В С\left(50 \Gamma^{\cdot} \pi^{-1}\right)$ & 1500 & 54 & 67 & 0,22 & 2 & 52 \\
\hline 4 & НПС $\left(300 \Gamma^{\cdot} \pi^{-1}\right) / \Pi В С\left(50 \Gamma^{\cdot} \pi^{-1}\right)$ & 2300 & 63 & 65 & 0,20 & 2 & 59 \\
\hline
\end{tabular}

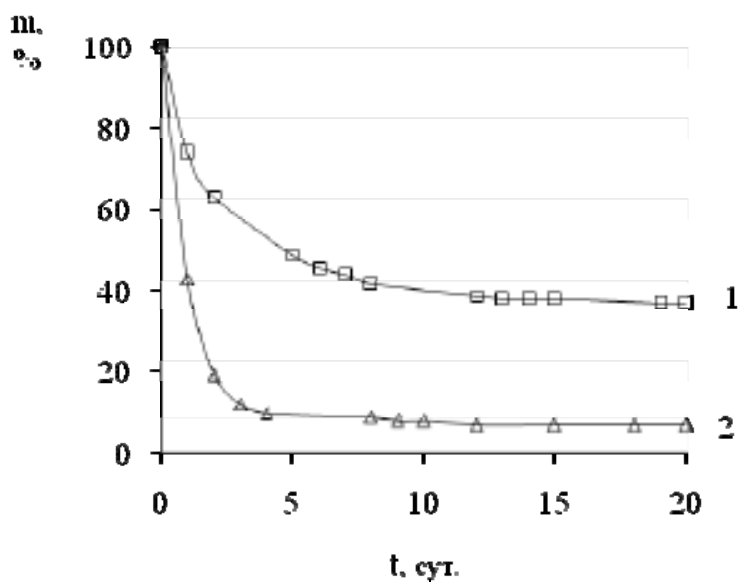

Состав криогелей: 1 - ПВС $100 \Gamma^{\cdot} \pi^{-1}$; НПС $300 \Gamma^{\cdot} \pi^{-1} ; 2$ - ПВС $100 \Gamma^{\cdot} \pi^{-1}$

Рис. 3. Изменение массы (m, \%) криогелей при хранении (t, сут) на воздухе

Fig. 3. Mass change (m, \%) of cryogels upon air storage (t, days)

Результаты контроля изменения массы двух образцов криогелей ПВС (содержащих НПС и без НПС), которые находились на открытом воздухе при комнатной температуре $\left(20^{\circ} \mathrm{C}\right)$ в течение нескольких суток, представлены на рис. 3.

Из данных рис. 3 следует, что примерно через 5 сут основная масса воды, находящейся в матрицах криогелей, испаряется и вес образцов становится постоянным. Следовательно, после дегидратации двухкомпонентного криогеля (вода - ПВС) в сухом остатке в виде жесткого и гидрофильного материала находится нелетучий ПВС, а в эластичном образце трехкомпонентного (наполненного) криогеля остаются ПВС и НПС. Именно наличие во втором образце нефтеполимерных смол придает ему эластичные и гидрофобные свойства.

Практический интерес представляют также криоструктураты с введенными в них твердыми дисперсными частицами, имеющими гидрофильный характер. В табл. 2 представлены составы исходных жидких композиций и результаты измерения механических (G) и теплофизических ( $\lambda$ ) свойств полученных из них криогелей, которые плотно наполнены сыпучими материалами: кварцевый песок, бентонит (глина) и цемент, а также дисперсии частиц этих материалов, предварительно смоченные гидрофобной жидкостью (раствором НПС) и затем пропитанные водным раствором ПВС. Из данных табл. 2 следует, что у образцов суспендиро- 
Таблица 2. Состав и свойства наполненных криогелей

Table 2. Composition and properties of filled cryogels

\begin{tabular}{|c|c|c|c|}
\hline \multirow{2}{*}{ № } & \multirow{2}{*}{$\begin{array}{c}\text { Состав исходной системы } \\
\text { для формирования криогеля }\end{array}$} & \multicolumn{2}{|c|}{ Свойства криогелей } \\
\hline & & $\mathrm{G}$, кПа & $\lambda, \mathrm{BT} /(\mathrm{K} \cdot \mathrm{M})$ \\
\hline 1 & Водный раствор ПВС $\left(50 \Gamma^{\circ} \cdot \pi^{-1}\right)$ & 11 & 0,34 \\
\hline 2 & $\begin{array}{l}\text { Водный раствор ПВС }\left(50 \text { г·л }{ }^{-1}\right) \\
\text { Песок }\end{array}$ & 629 & 0,36 \\
\hline 3 & $\begin{array}{l}\text { Водный раствор ПВС }\left(50 \text { г·л }{ }^{-1}\right) \\
\text { Песок, пропитанный нефтью }\end{array}$ & 150 & 0,35 \\
\hline 4 & $\begin{array}{l}\text { Водный раствор ПВС }\left(50 \Gamma^{\cdot} \cdot \pi^{-1}\right) \\
\text { Бентонит }\end{array}$ & 465 & 0,35 \\
\hline 5 & $\begin{array}{l}\text { Водный раствор ПВС }\left(50 \Gamma^{\cdot} \pi^{-1}\right) \\
\text { Бентонит, пропитанный нефтью }\end{array}$ & 345 & 0,34 \\
\hline 6 & $\begin{array}{l}\text { Водный раствор ПВС }\left(50 \Gamma^{\cdot} \pi^{-1}\right) \\
\text { Цемент }\end{array}$ & 885 & 0,37 \\
\hline 7 & $\begin{array}{l}\text { Водный раствор ПВС }\left(50 \Gamma^{\cdot} \pi^{-1}\right) \\
\text { Цемент, пропитанный нефтью }\end{array}$ & 416 & 0,35 \\
\hline
\end{tabular}

ванных криогелей резко возрастает жесткость (упругость) и практически не меняется коэффициент теплопроводности.

Наличие у материалов на основе криогелей из поливинилового спирта, наполненных нефтеполимерной смолой, хороших структурно-механических, теплоизоляционных и гидрофобных свойств позволяет использовать их в натурных условиях для гидроизоляции различных сооружений, а также при строительстве и ремонте дорог. Это особенно актуально в районах вечной мерзлоты и в условиях резко континентального климата при значительных перепадах дневных и ночных температур во влажной среде.

При строительстве современного дорожного полотна используют сложную конструкцию, которая в самом общем виде состоит из трех последовательных слоев: песок, щебень и асфальт. Вследствие капиллярной фильтрации песчаная и гравийная подложки, как правило, бывают насыщены влагой и при резкой смене температуры подвергаются заметным деформациям, что зачастую приводит к разрушению асфальтового покрытия. Лабораторными экспериментами показано, что после пропитки песчаной подложки раствором эмульсии (НПС/ ПВС) и последующего проведения в морозильной камере восьми циклов замораживания - оттаивания в интервале температур от минус $40{ }^{\circ} \mathrm{C}$ до $40{ }^{\circ} \mathrm{C}$ асфальтовое покрытие не отслаивается и сохраняет свою целостность вследствие образования промежуточного криогелевого слоя, обладающего демпфирующими и гидроизоляционными свойствами (рис. 4 и 5).

\section{Выводы}

1. Экспериментально установлено, что криогели, сформированные из прямой эмульсии «нефтеполимерная смола / поливиниловый спирт», обладают улучшенными механическими, теплофизическими и физико-химическими свойствами по сравнению с простыми двухкомпонентными криогелями, полученными из водного раствора поливинилового спирта. 


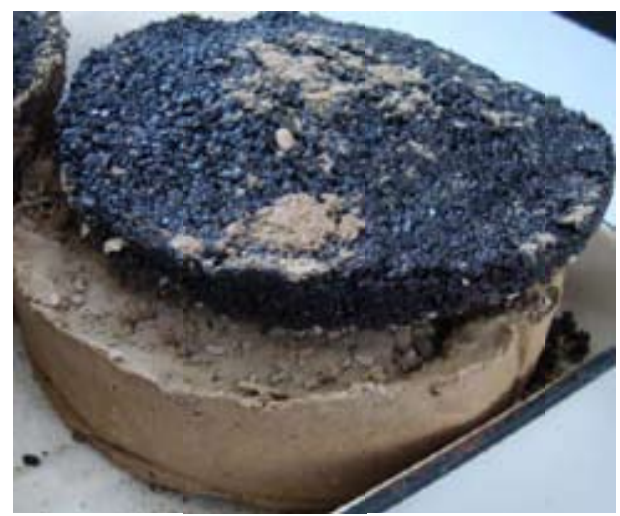

Рис. 4. Образец, содержащий криогель на основе ПВС

Fig. 4. A sample containing PVA-based cryogel

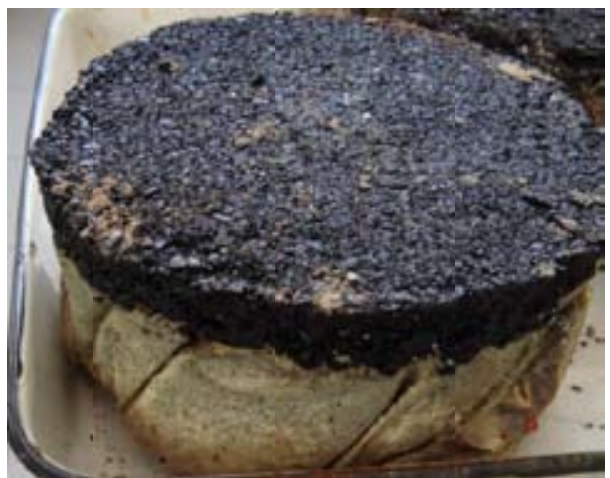

Рис. 5. Образец, содержащий криогель на основе ПВС и НПС

Fig. 5. A sample containing PVA- and NPS-based cryogel

2. Криогели состава «нефтеполимерная смола / поливиниловый спирт» с гидрофобными и упругими свойствами имеют высокую адгезию к минеральным веществам и могут быть рекомендованы в качестве связующего при бытовом и дорожном строительстве асфальтовых покрытий.

Работа выполнена в рамках проекта V.46.2.3. Физическая химия и реология нефти и полидисперсных нефтесодержацих систем в процессах увеличения нефтеотдачи пластов и транспорта нефти.

\section{Список литературы}

1. Лозинский В.И. Криотропное гелеобразование растворов поливинилового спирта. Успехи химии 1998. T. 67(7), C. 641-655. [Lozinsky V.I. Cryotropic gelation of poly(vinyl alcohol) solutions. Russian Chemical Reviews 1998. Vol. 67(7), P. 573-586. (In Russ.)]

2. Лозинский В.И. Криогели на основе природных и синтетических полимеров: получение, свойства и области применения. Успехи химии 2002. Т. 71(6), С. 559-585. [Lozinsky V.I. Cryogels on the basis of natural and synthetic polymers: preparation, properties and applications. Russian Chemical Reviews 2002. Vol. 71(6), P. 489-511. (In Russ.)]

3. Манжай В.Н., Фуфаева М.С. Свойства криогелей и их применение в технологиях добычи и транспорта нефти. Известия высших учебных заведений. Нефть и газ 2011. № 6, С. $102-$ 107. [Manzhai V.N., Fufaeva M.S. Properties of Cryogels and their Technological Application in Oil Production and Transportation. Oil \& Gas Journal 2011. No. 6, P. 102-107. (In Russ.)]

4. Алтунина Л.К., Кувшинов В.А., Долгих С.Н. Криогели для тампонажных работ в районах распространения многолетнемерзлых пород. Гидротехника 2010. № 3, С. 56-60. [Altunina L.K., Kuvshinov V.A., Dolgikh S.N. Cryogels for plugging in cold and permafrost regions. Gidrotechnika 2010. No. 3, P. 52-57. (In Russ.)]

5. Патент 2605112 (2016) РФ. Манжай В.Н, Алтунина Л.К. Фуфаева М.С., Бондалетов В.Г., Бондалетова Л.И. Гидроизоляционная композиция. Опубл. 20.12.2016. [Patent 2605112 (2016) 
RU Manzhai V.N., Altunina L.K., Fufaeva M.S., Bondaletov V.G., Bondaletova L.I. Waterproofing composition. Date of publication: 20.12.2016 (In Russ.)]

6. Лозинский В.И., Савина И.Н. Изучение криоструктурирования полимерных систем: 22. Композитные криогели поливинилового спирта, наполненные дисперсными частицами различной гидрофильности/гидрофобности. Коллоидный журнал 2002. Т. 64(3), С. 372-380. [Lozinskii V.I., Savina I.N. Study of cryostructuring of polymer systems: 22. Composite poly(vinyl alcohol) cryogels filled with dispersed particles of various degrees of hydrophilicity/hydrophobicity. Colloid Journal 2002. Vol. 64(3), P. 336-343. (In Russ.)]

7. Манжай В.Н., Фуфаева М.С. Рациональная утилизация отработанных масел с помощью криогелей на основе поливинилового спирта. Химия и технология топлив и масел 2015. № 5, C. 38-41. [Manzhai V.N. and Fufaeva M.S. Polyvinyl alcohol cryogels as an efficient spent-oil utilization method. Chemistry and Technology of Fuels and Oils 2015. No. 5, P. 38-41. (In Russ.)]

8. Алтунина Л.К., Манжай В.Н., Фуфаева М.С. Механические и теплофизические свойства криогелей и пенокриогелей, полученных из водных растворов поливинилового спирта. Журнал прикладной химии 2006. T. 79(10), C. 1689-1692. [Altunina L.K., Manzhai B.N., Fufaeva M.S. Mechanical and thermal properties of cryogels and foamed cryogels produced from aqueous solutions of poly(vinyl alcohol). Russian Journal of Applied Chemistry 2006. Vol. 79(10), P. 1669-1672. (In Russ.)]

9. Ермизин К.В., Бондалетов В.Г., Ляпков А.А. и др. Получение широкого ассортимента углеводородных олигомеров на основе кубовых продуктов колонны К-27 установки ЭП300. Химическая промышленность 2009. Т. 86(6), С. 304-313. [Ermizin K.V., Bondaletov V.G., Lyapkov A.A. etc. Obtaining a widerange of hydrocarbon oligomers based on the bottom products of the K-27 column of the EP-300 unit. Khimicheskaya promyshlennost 2009. T. 86 (6), P. 304-313. (In Russ.)]

10. Думский Ю.В., Но Б.И., Бутов Г.М. Химия и технология нефтеполимерных смол. М.: Химия, 1999. 312 с. [Dumsky Yu.V., No B.I., Butov G.M. Chemistry and technology of petroleum resins. M.: Chemistry, 1999. 312 p. (In Russ.)]

11. Фитерер Е.П., Бондалетов В.Г., Бондалетова Л.И. Полимеризация высококипящих фракций пироконденсата на каталитических системах типа Циглера-Натта. Известия высших учебных заведений. Химия и химическая технология 2004. Т. 47(1), С. 127-130. [Fiterer E.P., Bondaletov V.G., Bondaletova L.I. Polymerization of high boiling pyrocondensate fractions on Ziegler-Natta type catalyst systems. Izvestiya vysshikh uchebnykh zavedeniy. Chemistry and chemical technology 2004. Vol. 47(1), P. 127-130. (In Russ.)]

12. Абрамзон А.А., Зайченко Л.П., Файнгольд С.И. Поверхностно-активные вещеества. Л.: Химия, 1988. 200 c. [Abramzon A.A., Zaichenko L.P., Faigold S.I. Surfactants. L .: Chemistry, 1988. 200 p. (In Russ.)]

13. Лозинский В.И., Сахно Н.Г., Дамшкалн Л.Г. и др. Изучение криоструктурирования полимерных систем: 31. Влияние добавок хлоридов щелочных металлов на физико-химические свойства и морфологию криогелей поливинилового спирта. Коллоидный журнал 2011. Т. 73(2), C. 225-234. [Lozinsky V.I., Sakhno N.G., Damshkaln L.G., Bakeeva I.V., Zubov V.P., Kurochkin I.N. Study of cryostructuring of polymer systems: 31. Effect of additives of alkali metal chlorides on physicochemical properties and morphology of poly(vinyl alcohol) cryogels. Colloid Journal 2011. Vol. 73(2), P. 234-243. (In Russ.)] 
14. Касаткин А.Г. Основные проиессы и аппараты химической технологии. М.: Химия, 1971. 784 c. [Kasatkin A.G. Basic processes and apparatuses of chemical technology. M.: Chemistry, 1971. 784 p. (In Russ.)]

15. Кутателадзе С.С. Справочник по теплопередаче. М.: Химия, 1959. 416 с. [Kutateladze S.S. Handbook of heat transfer. M.: Chemistry, 1959. 416 p. (In Russ.)] 